\title{
Can we eliminate nutritional anemia in the near future?
}

\author{
Palash Das
}

Associate Professor, Department of Community Medicine, College of Medicine and Sagore Dutta Hospital, Kolkata, West Bengal, India

Lowered level of hemoglobin causes anemia which is clinically represented by pallor and weakness. ${ }^{1}$ The 'nutritional anemia' includes all abnormal conditions in which the blood hemoglobin concentration drops down to an abnormally low level due to a deficiency in one or several nutrients. Iron is a part of hemoglobin and synthesis of hemoglobin requires folic acid, vitamin $B_{12}$ etc. Iron deficiency is the commonest cause of nutritional anemia. ${ }^{2}$ Folic acid deficiency and Vitamin $\mathrm{B}_{12}$ deficiency is not so common. Iron-deficiency anemia should be focused as a priority in all groups of people including children.

Hemoglobin $(\mathrm{Hb})$ thresholds are used to classify individuals living at sea level as anemic (Table 1). ${ }^{3}$ Anemia can be categorized as mild (hemoglobin level $<$ normal to $10 \mathrm{gm} \%$ ), moderate (hemoglobin level $<10$ to $7 \mathrm{gm} \%$ ) and severe (hemoglobin level $<7 \mathrm{gm} \%$ ) for all age and sex groups of people. ${ }^{4}$

Anemia is affecting around two billion people, including 800 million children under the age of 5 and women of reproductive age worldwide, mostly due to nutritional iron deficiency. ${ }^{2,5-7}$ Women are the most affected group of population in the absolute figures. ${ }^{5,8} \mathrm{~A}$ significant percentage $(27 \%)$ of adolescents in the developing world are also reported to be anemic, compared to $6 \%$ in developed countries. ${ }^{9}$ Anemia is an emerging problem in the elderly population too, negatively impacting the quality of life. ${ }^{10}$ Combating the situation of anemia among elderly people is a challenge as adding life to their years is not given an appropriate

Table 1: Hemoglobin threshold levels in different age, gender and physiological status

\begin{tabular}{|l|c|}
\hline \multicolumn{1}{|c|}{ Age or gender group } & $\begin{array}{c}\text { Hemoglobin } \\
\text { threshold gm } \\
\mathbf{( \% )}\end{array}$ \\
\hline Children (0.50-4.99 yrs) & 11.0 \\
\hline Children (5.00-11.99 yrs) & 11.5 \\
\hline Children (12.00-14.99 yrs) & 12.0 \\
\hline Non-pregnant women ( $\geq 15.00$ yrs) & 12.0 \\
\hline Pregnant women & 11.0 \\
\hline Men ( $\geq 15.00$ yrs) & 13.0 \\
\hline
\end{tabular}

amount of importance. It can be safely declared that inter-country and intra-country variation of anemic people is present at any point of time. Regional differences might be due to presence of known and some unknown determinants prevalent in that particular area. $^{5}$

Now the question: Why are women primarily affected by anemia? Is it physiological or due to physiological blood loss every month? The answer may be found through research. Though prevalence rates of anemia are closer for males and females in some parts of the world among adolescents, the prevalence of anemia is disproportionately high in developing countries. ${ }^{5}$ The common indirect causes of anemia may be poverty, poor education, lack of dietary knowledge leading to an inadequate, imbalanced diet, worm infestations, repeat pregnancy and lactation, and poor access and utilization of health services. ${ }^{11}$ Vulnerable populations are abnormally high in number in developing countries. The burden of anemia so is observed abnormally high in poverty stricken developing countries. ${ }^{5}$

The International Centre for Research on Women conducted a large study on adolescent health and this study discovered anemia in all the countries in a palpable proportion (India: 55\%, Nepal: 42\%, Cameroon: $32 \%$, Ecuador: 17\%, Jamaica: 16\%). All these documents highlight the real situation of anemia status throughout the globe. ${ }^{9}$ The prevalence of anemia among adolescent was found to be $35-90 \%$ in India ${ }^{12,13}$ Pregnant women also show a high proportion of anemia $(84.9 \%)$ in India. ${ }^{14}$ Primary school children (6-10 years) show lower levels of anemia $(22.3 \%-32.79 \%)$ in a city of the eastern part of India. ${ }^{15,16}$

\section{Health consequences of anemia}

Anemia adversely affects physical and mental growth. In pregnancy it is associated with abortions, premature births, low birth weight, failure to thrive, and perinatal and maternal morbidity and mortality. ${ }^{2,7}$ Anemia is an indicator of both poor nutrition and poor health. The most dramatic health effects of anemia, i.e. increased risk of maternal and child mortality due to severe anemia, have been well documented. ${ }^{2}$ In addition, the negative consequences of Iron Deficiency Anemia on cognitive and physical development of children and on physical performance - particularly work productivity

Correspondence: Dr Palash Das, Associate Professor, Department of Community Medicine, College of Medicine and Sagore Dutta Hospital, Kolkata, West Bengal, India. E-mail: palashdasdr@gmail.com. 
in adults - are of major concern. ${ }^{3}$ Significant impairment of work capacity is caused by anemia and thereby productivity and ultimately anemic nation will show low level of country economy.

\section{Strategies to combat anemia}

Short term actions

Treatment: Anemia affected persons should be treated with proper dose of micronutrients for a certain period.

Iron supplementation: Appropriate amount of Iron salt should be given to the vulnerable groups (young children, pregnant women) for a definite time period to prevent anemia.

Folic acid Supplementation: Few cases will be benefitted where iron deficiency is not the only cause.

Dosage schedule: 6-60 months children: $20 \mathrm{mg}$ elemental iron and $100 \mathrm{mcg}$ folic acid; 6-10 years children: $30 \mathrm{mg}$ elemental iron and $250 \mathrm{mcg}$ folic acid; 11-18 years children: $100 \mathrm{mg}$ elemental iron and 500 $\mathrm{mcg}$ folic acid; Pregnant women, nursing mothers, acceptors of family planning methods: $100 \mathrm{mg}$ elemental iron and $500 \mathrm{mcg}$ folic acid. ${ }^{17}$ Strategies can be built into the primary health care system and existing programs such as maternal and child health, integrated management of neonatal and childhood illness, adolescent health, making pregnancy safer/safe motherhood, roll-back malaria, deworming etc.

Deworming: Anthelmentic control measure should be routine activity for the vulnerable group to prevent worm infestation in order to prevent anemia. Albendazole should be the choice of drugs as it requires considerably low motivation for single dose in comparison with multiple doses of mebendazole.

Maternal health: Treatment of anemic mothers, iron and folic acid supplementation to prevent anemia, adoption of family planning method to prevent repeated low spaced pregnancy, infection and parasitosis control, balanced diet in pregnancy are few of the common measures which can keep away from iron deficiency disorders.

\section{Long term actions}

Health facilities: Health facilities like health centers, clinics and hospitals can offer information about source, consumption, absorption and utilization of iron improving and iron status. They should provide services for screening of anemia among all the attending female patients and accordingly treatment can be provided.

Health (nutrition) education: Attention must be paid to increasing awareness and knowledge among health care providers and the general public concerning the health risks associated with anemia. They should be encouraged to adopt food consumption methods that provide sufficient amounts of iron, folic acid, vitamin $\mathrm{B}_{12}$ etc. Educational settings like schools can incorporate nutrition education in their course curriculum. This educational session may put good and sustainable practice impact among this group. Peer education projects, workplace educational sessions, and social/recreational activities and other community activities can incorporate nutrition education into their programs with emphasis on iron deficiency anemia.

Food-based approaches: Food fortification and dietary modifications in need may be important sustainable strategies for preventing iron deficiency and iron deficiency anemia in the general population. Strategies should be tailored to local conditions and take into account the specific etiology and prevalence of anemia in a given setting and population group.

Political commitment: Political leaders who are framing strategy, taking decision, planning for action should give priority to the problems of relevant sectors like health to battle the war.

Use of media: Practical and attractive information about iron needs can be communicated to general people through the mass media like radio, television, movies, print materials as well as through traditional media like folk drama, fairs, puppet shows, plays.

Inbuilt evaluation: Program will be taken to alleviate anemia with monitoring activity in order to assess prevalence, effectiveness of intervention. With the above principles in mind, countries should develop and implement a package of integrated core interventions based on local conditions to achieve the goal of reducing by one third the prevalence of anemia that the United Nations General Assembly adopted at its special session on children. ${ }^{18}$

\section{Concluding remarks}

The relation between human productivity and the national economy is intimately proportional. ${ }^{19}$ One of the important health problems is nutritional anemia which is highly prevalent in most of the countries irrespective of caste, creed, education, economy etc. Poorer countries are more affected with nutritional anemia. So productivity of poorer countries is worse than that of developed counties. The health sector is associated with socially and economically productive life. Health care providers (front line workers to doctors) and health managers should go for advocacy to adopt activities by decision maker, planner of the country in all possible level. Planning should be done taking care of anaemic sufferers and to prevent anemia providing elementary iron and anthelmintic to the vulnerable population. And really, this is feasible in terms of support, affordability, acceptability by the people, inventory control etc. Lack of awareness of people about nutrient deficiency, its complications, low consumption of iron containing food, lack of effective education programs by planners and policy makers found in some similar study ${ }^{20}$ demand immediate therapeutic and prophylactic program for correction of the nutritional anemia. 


\section{References}

1. Illustrated Oxford Dictionary. Special Edition. New Delhi: Penguin Books India, 2006.

2. Barclay EG, Tiwari K. Prevention and Control of Nutritional Anaemia: A South Asia Priority. New Delhi: United Nations Children's FundRegional Office for South Asia, 2002.

3. WHO; CDC. Worldwide prevalence of anaemia 1993-2005. WHO Global database on anaemia. Geneva: World Health Organization, 2008.

4. WHO. Haemoglobin concentrations for the diagnosis of anaemia and assessment of severity. Vitamin and Mineral Nutrition Information System. WHO/NMH/NHD/MNM/11.1. Geneva: World Health Organization, 2011.

5. WHO. The global prevalence of anaemia in 2011. Geneva: World Health Organization, 2015.

6. Kotecha PV. Nutritional anemia in young children with focus on Asia and India. Indian $J$ Community Med 2011;36(1):8-16.

7. WHO. Nutrition. Micronutrient deficiencies. http://www.who.int/nutrition/topics/ida/en/ (accessed June 2015)

8. WHO. National Strategies for Overcoming Micronutrient Malnutrition. Geneva: World Health Organization 1991,

9. In Focus. Young People and Anemia. http:// www2.pathfinder.org/pf/pubs/focus/IN\% 20FOCUS/Anemia.html (accessed June 2015)

10. Agarwala R. Anaemia in elderly: The need to combat the problem. Ind J Com Med 2014;39(3) 187-8.

11. Bakeera SK, Wamala SP, Galea S, State A, Peterson S and Pariyo GW. Community perceptions and factors influencing utilization of health services in Uganda. Int $J$ Equity Health 2009;8:25.
12. Chaudhary SM, Dhage VR. A study of anemia among adolescent females in the urban area of Nagpur. Indian J Community Med 2008;33:2435 .

13. Naidu CS, Venela P, Ammika P, Kattula SR, Kokkiligadda SV, Deshmukh H. Factors influencing anaemia among adolescent girls from urban slums of Hyderabad - A cross-sectional cohort study. Indian J Pubic Health Res Dev 2014;5(3):16-21.

14. Toteja GS, Singh P, Dhillon BS, Saxena BN, Ahmed FU, Singh RP, et al. Prevalence of anemia among pregnant women and adolescent girls in 16 districts of India. Food Nutr Bull 2006;27(4):311-5.

15. Das P, Basu M, Dhar G, Mallik S, Pal R. Nutritional status and morbidity pattern of government primary school children in north Kolkata of West Bengal, India. South East Asia J Public Health 2012;2(1):13-7.

16. Das P, Basu M, Dhar G, Pal R. Somatic Profile of North Kolkata school students. Healthline 2012;3(2):18-21.

17. Taneja DK. Health policies and programmes in India. $11^{\text {th }}$ Edition. New Delhi: Doctors Publications, 2013.

18. Young M, Wolfheim C, Marsh DR, Hammamy D. World Health Organization/United Nations Children's Fund Joint Statement on Integrated Community Case Management: An EquityFocused Strategy to Improve Access to Essential Treatment Services for Children. Am J Trop Med Hyg 2012;87(5 Suppl):6-10.

19. Wikipedia. Economic Growth. https:// e n.wiki pedia.org/w i k i / Economic growth\#Productivity (accessed June 2015)

20. Subhan F, Jahangir M, Saira S, Khattak RM, Shahab M, Haq M, Khattak MNK. Prevalence of goiter and iodine status among 6-12 years school age children in district Kohat, Pakistan. South East Asia J Public Health 2014;4(2):42-6. 